East African Medical Journal Vol. 86 No. 6 June 2009

POST-PRANDIAL GLUCOSE LEVELS AND CONSUMPTION OF OMEGA 3 FATTY ACIDS AND SATURATED FATS AMONG TWO RURAL POPULATIONS IN KENYA

V. W. Wanjihia, MPH, Research Officer, Centre for Public Health Research, Kenya Medical Research Institute, P. O. Box 20752-00202, Nairobi, Kenya, F. K. Kiplamai, MSc, Lecturer, Department of Exercise, Recreation and Sports Science, Kenyatta University, P. O. Box 43844-00100, Nairobi, Kenya, J. N. Waudo, PhD, Dean, Graduate School, Kenyatta University, P. O. Box 43844-00100, Nairobi, Kenya and M.K. Boit, PhD, Director, International Athletics Association Federation Academy (IAAF Academy), Kenyatta University, P. O. Box 43844-00100, Nairobi, Kenya

Request for reprints to: Mr. F. K. Kiplamai, Department of Exercise, Recreation and Sports Science, Kenyatta University, P. O. Box 43844-00100, Nairobi, Kenya

\title{
POST-PRANDIAL GLUCOSE LEVELS AND CONSUMPTION OF OMEGA 3 FATTY ACIDS AND SATURATED FATS AMONG TWO RURAL POPULATIONS IN KENYA
}

\author{
V. W. WANJIHIA, F. K. KIPLAMAI, J. N. WAUDO and M. K. BOIT
}

\begin{abstract}
Background: Amount and quality of dietary fat modifies glucose tolerance. Omega 3 Fatty Acids (n-3F A) are polyunsaturated fats, mainly eicosapentaenoic acid (EPA) and docosahexaenoic acid (DHA) found primarily in fish and they have a positive effect on glucose tolerance.

Objective: To compare risk of type 2 diabetes mellitus (T2DM), as demonstrated thourough impaired glucose tolerance (IGT), and n-3FA intake among two rural populations.

Design: A descriptive, cross-sectional comparative study.

Setting: Bondo District (Luo Community) and Kericho District (Kipsigis Community) of the Lake Victoria basin of Kenya.

Subjects: Sample of 150 individuals, aged above 18 years was randomly selected from each of the two communities.

Interventions: Impaired glucose tolerance (IGT) was measured according to World Health Organisation diagnostic criteria. The intake of n-3FA was determined using a 24 hour dietary recall and food frequency schedule. Data was analysed using SPSS and Pearson Correlation Coefficient was used to test correlation between n-3FA consumption and IGT. The inter-group comparisons were done using the t-test and analysis of variance.

Results: The prevalence of IGT was $11.8 \%$ among the Kipsigis and $4.8 \%$ among the Luo $(\mathrm{P}<0.001)$. The mean EPA and DHA intake was found to be $0.29 \mathrm{~g} / \mathrm{day}$ and $0.34 \mathrm{~g} / \mathrm{day}$ respectively among the $L u$ and $0.01 \mathrm{~g} /$ day and $0.01 \mathrm{~g} /$ day among the Kipsigis $(\mathrm{P}<0.001)$. The relationship between 2 hour post-prandial glucose level and consumption of DHA was $(r=-0.111, p<0.05)$, EPA $(r=-0.123, p<0.05)$, polyunsaturated fatty acids $(r=-0.128$. $\mathrm{p}<0.05)$ and saturated fats $(\mathrm{r}=-0.002, \mathrm{p}=0.973)$.

Conclusion: The levels of IGT were significantly lower $(\mathrm{P}<0.001)$ among the Luo, than among the Kipsigis. There was also evidence of significant inverse relationship between IGT and consumption of n-3FA and polyunsaturated fatty acids (PUFA) but no association between saturated fats intake and IGT. The saturated fat ingested did not affect the level of post-prandial glucose. The Luo who consumed higher n-3FA amounts, recorded lower levels of IGT than the Kipsigis who had significantly lower consumption.

Recommendations: Effective screening methods should be used at the existing health units to determine risk factors of type 2 diabetes mellitus like IGT among patients. This could help in advising them accordingly on lifestyle changes, especially concerning diet and beneficial fats.
\end{abstract}




\section{INTRODUCTION}

Diabetes mellitusis a metabolic disorder characterised by chouronic hyperglycaemia with disturbances in carbohydrate, fat and protein metabolism, arising from a defect in insulin secretion, or cell insensitivity to its action (1). Impaired glucose tolerance forms an intermediate stage in the natural history of Type 2 Diabetes Mellitus (T2DM). It is defined as twohour post-prandial blood glucose levels of between $7.8-11.0 \mathrm{mmol} / 1$ on the $75 \mathrm{~g}$ oral glucose tolerance test, according to WHO diagnostic criteria (1). These glucose levels are above normal blood glucose level but lower than the level that is diagnostic for diabetes, which is $>11.0 \mathrm{mmol} / 1$ on the $75 \mathrm{~g}$ oral glucose tolerance test. Presence of impaired glucose tolerance (IGT) among a population suggests an early stage of a diabetes epidemic. With the predicted increase in type 2 diabetes, approximately by $50 \%$ (from 9.4 million to 14.1 million) between 2001 and 2010 in Africa alone, it is possible that a large percentage of the populations, in both rural and urban areas may be in the pre-diabetic stage (2-5). Patients with impaired glucose tolerance have a significant risk of developing diabetes and thus they can be termed as having a high susceptibility, risk or pre-disposition to type 2 diabetes mellitus $(6,7)$.

Prevalence of T2DM in rural areas in Africa remains low however the urban areas are experiencing elevated prevalence levels. This was demonstrated in a preliminary community survey for diabetes in the Bo district of southern Sierra Leone where there was a prevalence of $2.4 \%$ in the urban population, and $0 \%$ in the rural populations (2). In Bangladesh, a higher prevalence of diabetes of $8.1 \%$ has also been found in urban compared to $2.3 \%$ in the rural populations (8).

In some rural areas nevertheless, diabetes is increasingly becoming a public health concern. Type 2 diabetes mellitus has been identified as the third highest ranking rural health concern (9). It is therefore crucial to have the risk factors of the rural inhabitants, especially in a sub-Saharan African country explored, so as to avert the danger it may cause. Clinically, early detection of diabetes provides an opportunity to reduce the progression of microvascular or macrovasular diseases caused by asymptomatic hyperglycaemia.

Type 2 diabetes mellitus (T2DM) can be aptly named a "bad food disease" in combination with other lifestyle factors and a susceptible genotype (3). Our bodies need fat, however, it must be the right kind of fat. Both the amount and quality of dietary fat may modify glucose tolerance and insulin sensitivity. A high saturated fat content in the diet may result in deterioration of glucose tolerance by mechanisms like decreased binding of insulin to its receptors and consequently impaired glucose transport.

Higher proportions of saturated fatty acids intake have also been associated with higher fasting insulin concentrations (11) and a lower insulin sensitivity index and consequently, higher risk of type 2 diabetes (12). On the other hand, there are several studies, which show no association between diabetes risk and total fat intake (13-15).

Purpose of the study: Omega-3-fatty acids are a form of polyunsaturated fats, mainly eicosapentaenoic acid (EPAC 20,5) and docosahexaenoic acid (DHAC22,6), both found primarily in fish. They are increasingly recognised as important to human health but it is not yet clear how beneficial they can be in averting the risk of T2DM (10). The purpose of this study was therefore to establish how the risk of T2DM, as demonstrated thourough post- prandial glucose levels, is brought about by dietary saturated fat intake vis-a-vis the intake of polyunsaturated fats like n-3F A.

It was also important to establish the prevalence of IGT in the rural areas among populations of varying dietary practices. The current study reports on the consumption of saturated fats, polyunsaturated fats and omega-3-fatty acids and compares these factors to the levels of post-prandial glucose among two rural populations in Kenya.

\section{MATERIALS AND METHODS}

Study population and design: A cross-sectional survey was conducted in Nyangoma Division, Bondo District and in Soin Division, Kericho District of the Lake Victoria Basin in Kenya. Both regions have similar climatic patterns and temperature levels. They however are occupied by communities from two different agricultural and cultural backgrounds. In the study areas all administrative locations, sublocations, villages and homesteads were listed from the demographic data available from the latest surveys by the Kenya National Bureau of Statistics (16) and with the help of the area chiefs, assistant chiefs and village elders. All households with adults aged between 18-60 years were equally listed. From this listing, SPSS was then used to generate a random list of households and individuals from which the study sample was drawn. The sampling frame was the list of adults meeting the inclusion criteria in each homestead. Assuming a refusal rate of $10 \%$ a random sample of 150 individuals was selected from each of the communities.

The sample size calculation was based on the formula for adequate power to detect differences in proportions. To compare the means of variables determined between the two independent 
populations, the sample was calculated using the Gpower statistical power determination programme created by Faul et al., (17). The random sample of 150 individuals from each of the communities of the Lake Victoria basin was used as study subjects. Using a medium effect rate of $0.25, \alpha=0.05$ and a non-sphericity correlation of 0.5 (17), the study had considerably high power (>95\% confidence level) to detect the changes within the variables and differences between the two communities.

Diagnosis of impaired glucose tolerance: Diagnosis of impaired glucose tolerance (IGT) and diabetes was done based on fasting blood glucose (FBG) sample and IGT according to WHO diagnostic criteria (1). After the initial blood sample to determine fasting blood glucose, the subject was given an oral glucose load $(75 \mathrm{~g})$ and blood collected again after 2 hours. The Accu- Chek Glucose meter (Roche Diagnostics, Indianapolis, IN) with Accu-Chek-plus test- strips was used to determine blood sugar level. Anyone who had a fasting blood glucose reading of over 6.9 $\mathrm{mmol} / \mathrm{l}$ was not subjected to an OGTT due to their likelihood of being an undiagnosed diabetic.

Dietary assessment: A 24 hour recall interview that required the participant to recall all that they had ingested in the previous 24 hours, including snacks and fluids, from morning after rising, to evening. To be recorded was the time the meal was ingested, where it was eaten, the type of food, ingredients used and method of preparation, as well as the serving amounts. The amounts were indicated in household units and measures, for instance cups and mugs. These utensils would be taken from the household prior to the study and pre-weighed with the amounts of food frequently consumed in that household, so that a code for a particular intake could be predetermined. For foods where this was not possible, then actual food samples were provided during the interview so that the participant could demonstrate their recalled intake, which would then be weighed. Models of standardised portions were also used to define and describe amounts of food eaten by the participants. This way the 24 hour recall schedule, would provide both quantitative and qualitative information on dietary intake. The Nutri-survey programme which was used for nutrient analysis was then used to calculate how much n-3F A, saturated fats or PUF As had been ingested by each person.

Mobilisation and ethical consideration: Study participants were mobilised with the help of the local administration that is the District Officer, the chiefs and village elders in the study areas. The sampled populations were advised on the date to report to the screening and interview centre. On the reporting day, the participants were required to report early in the morning without having taken breakfast and after an overnight fast, of at least eight hours. Written informed consent was obtained from each participant. The participant was given the consent form which appeared in a language that they could understand. Voluntary participation was further emphasized. If they could not read, then a trusted aide would read and interpret the information given. Thisinformation included; aims, methods, the anticipated benefits and any discomfort the study entails.

The participant was also informed of the right to abstain from participation in the study or to withdraw at any time without reprisal or loss of care and confidentiality was strictly observed. After the participant consented, they signed the consent form or appended a thumb print. Interviews were carried out to provide general socio- demographic information. The study was approved and granted ethical clearance by the National Ethical Review Board at the Kenya Medical Research Institute (KEMRI).

Statistical analysis: Data were analysed using SPSS version 11.5 and Nutri-Survey Programme. The existing Nutri-Survey Programme was modified accordingly using local food composition tables (18) indicative of the n-3 FA levels in the local foods ingested in the study areas. On input of the amount of food ingested by a study subject, from the 24 hour recall schedule, the Nutri-Survey programme was able to calculate how much n-3FA, saturated fats or PUF As had been ingested by each person. The programme was also able to calculate the mean consumption of nutrients such as protein, energy, Vitamin A and iron. Pearson correlation coefficient was used to test correlation between n-3FA. PUF A and saturated fats consumption and prevalence of IGT. The inter-group comparisons were performed by using an independent-sample t-test and a oneway analysis of variance followed by Duncan's Multiple Range Test. Descriptive statistics like mean, frequencies, percentages were used to describe data and comparative line graphs to present data.

\section{RESULTS}

Prevalence ofIGT: The prevalence of impaired glucose tolerance (IGT) was $4.8 \%$ and $11.8 \%$ for the Bondo and Kericho population respectively. The Bondo population reported none of the subjects falling within the diabetic range of above $11.1 \mathrm{mmol} / \mathrm{l}$. The Kericho population had $1.3 \%$ of the participants within the diabetic range.

The mean 2 hour blood glucose value after the oral glucose tolerance test was significantly higher in the Kericho $(6.4 \mathrm{mmol} / \mathrm{l})$ than in the Bondo population $(5.5 \mathrm{mmol} / 1)$, with a $\mathrm{p}<0.05$. 
Table 1

Composition of the study population

\begin{tabular}{lll}
\hline Locality & Sex & No. \\
\hline \multirow{2}{*}{ Bondo } & Male & 66 \\
& Female & 83 \\
\hline Total & 149 \\
\hline Kericho & Male & 68 \\
& Female & 82 \\
\hline Total & 150 \\
\hline
\end{tabular}

Table 2

Composition of the study population according to age groups

\begin{tabular}{llll}
\hline Age categories & Luo & Kipsigis & Total \\
\hline $18-30$ & 39 & 52 & 91 \\
$31-40$ & 32 & 30 & 62 \\
$41-50$ & 30 & 26 & 56 \\
$51-60$ & 29 & 23 & 52 \\
$>60$ & 19 & 19 & 38 \\
\hline
\end{tabular}

IGT levels among males and females:The mean 2 hour blood glucose value after the oral glucose tolerance test was significantly higher for women than for men in both the Bondo and Kericho, at $6.2 \pm 1.2$ for women $(\mathrm{n}=165)$ and $5.6 \pm 1.2(\mathrm{n}=134)$ for men $(\mathrm{p}<0.001)$. The women in Kericho also demonstrated higher levels of 2 hour post-prandial glucose, than their Bondo counterparts $(p<0.001)$. The same is true for the Kericho men against their Bondo counterparts, also at very significant levels $(p<0.001)$. In Bondo, the males demonstrated lower levels $(5.2 \pm 1.3 \mathrm{mmol} / \mathrm{L})$ of 2 hour post- prandial glucose than females $(5.8 \pm 1.0$ $\mathrm{mmol} / \mathrm{L}) \mathrm{p}<0.001$. It was the same case in Kericho, with the men at a mean of $6.1 \pm 1.5 \mathrm{mmol} / \mathrm{L}$ and women $6.7 \pm 1.2 \mathrm{mmol} / \mathrm{L}, \mathrm{p}<0.001$.

IGT levels among age groups: There was no significance difference in the mean 2 hour post-prandial glucose among the age categories. The results also indicate no significant correlation between age and the mean 2 hour post-prandial glucose. Nevertheless, the highest prevalence of IGT was recorded among the age-group 51-60 years.

Table 3

Prevalence of impaired glucose tolerance among both populations

\begin{tabular}{lllll}
\hline Locality & $\begin{array}{l}\text { Mean 2 hour blood } \\
\text { glucose Mmol/1 }\end{array}$ & $\begin{array}{l}\text { Mmour } / 1 \\
(\%)\end{array}$ & $\begin{array}{l}2 \text { hour } 7.8-11.1 \\
(\mathrm{IGT}) \text { Mmol } / 1 \\
(\%)\end{array}$ & $\begin{array}{l}2 \text { hour }>11.1 \\
\text { (Diabetics) Mmol/1 } \\
(\%)\end{array}$ \\
\hline $\begin{array}{l}\text { Bondo } \\
(\mathrm{n}=149)\end{array}$ & $5.5 \pm 1.2$ & 95.2 & 4.8 & 0 \\
$\begin{array}{l}\text { Kericho } \\
(\mathrm{n}=150)\end{array}$ & $6.4 \pm 1.4$ & 95.4 & 11.8 & 1.3 \\
\hline $\mathrm{P}<0.001$ & & &
\end{tabular}

Table 4

Mean 2 hour blood sugar level and prevalence impaired glucose tolerance in both sexes

\begin{tabular}{llll}
\hline Locality & Sex & Mean in Mmol/1 & IGT Prevalence (\%) \\
\hline \multirow{2}{*}{ Bondo } & Male $(\mathrm{n}=66)$ & $5.2 \pm 1.3^{\mathrm{a}}$ & 3.1 \\
& Female (n=83) & $5.8 \pm 1.0^{\mathrm{b}}$ & 6.0 \\
\multirow{3}{*}{ Kericho } & Male $(\mathrm{n}=68)$ & $6.1 \pm 1.5^{\mathrm{b}}$ & 4.4 \\
& Female (n=82) & $6.7 \pm 1.2^{\mathrm{c}}$ & 17.9 \\
\hline
\end{tabular}

${ }^{*}$ The test of significance was done using the t-test.

Means with the same letter superscript (Superscript a or b) are not significantly different. Those with different letter superscript are significantly different $\mathrm{P}<0.001$ ) 


\section{Figure 1}

Two hour post-prandial glucose among males and females per district

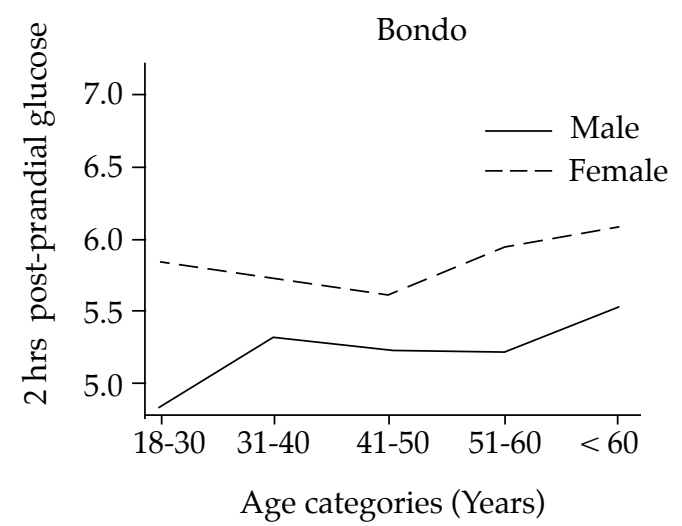

Table 5

Two hour mean blood glucose per age category

\begin{tabular}{lll}
\hline $\begin{array}{l}\text { Age } \\
\text { category (years) }\end{array}$ & $\begin{array}{l}\text { Mean } \\
(\text { Mmol/L) }\end{array}$ & $\begin{array}{l}\text { IGT } \\
\text { Prevalence }(\%)\end{array}$ \\
\hline $18-30$ & $5.78(0=91)$ & 5.5 \\
$31-40$ & $6.02(0=62)$ & 9.7 \\
$41-50$ & $6.05(0=56)$ & 8.9 \\
$51-60$ & $5.87(0=52)$ & 12.0 \\
Above 60 years & $6.12(0=38)$ & 5.3 \\
\hline
\end{tabular}

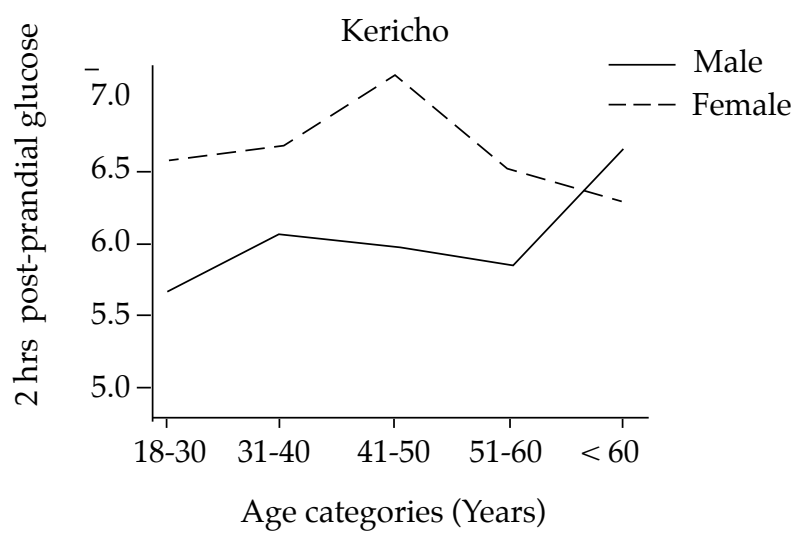

Consumption of $n-3 F A, P U F A$ s and saturated fats: Two components of n-3F A that are found in fish, Eicosapentaenoic Acid (C 20, 5) and Docosahexaenoic Acid (C 22, 6) were found to be consumed in Bondo at a mean of $0.29 \mathrm{~g}$ and $0.34 \mathrm{~g}$ per day respectively. In Kericho, the mean consumption for both EPA and DHA was, $0.01 \mathrm{~g}$ for each. The consumption of both DHAand EPA was higher in Bondo than in Kericho $(\mathrm{P}<0.001)$.

Other polyunsaturated fatty acids (PUF As) were found to be consumed at a mean of $1.91 \mathrm{~g}$ and $1.14 \mathrm{~g}$ for Bondo and Kericho respectively. Saturated fats were consumed at a mean of $3.8 \mathrm{~g}$ and $6.7 \mathrm{~g}$ for both Bondo and Kericho respectively. There was a highly significant difference between consumption of $n-3 F A, P U F$ As and saturated fats in the two districts (Table 6).

Table 6

Consumption of EPA and DHA among the rural and urban population

\begin{tabular}{|c|c|c|c|c|c|c|}
\hline Locality & & $\begin{array}{l}\text { EPA(C 20,5) } \\
\text { (g) }\end{array}$ & $\begin{array}{l}\text { DHA (C 22,6) } \\
\text { (g) }\end{array}$ & $\begin{array}{l}\text { Total n-3FA } \\
\text { (g) }\end{array}$ & $\begin{array}{l}\text { PUFAs } \\
\text { (g) }\end{array}$ & $\begin{array}{l}\text { Saturated Fats } \\
\text { (g) }\end{array}$ \\
\hline Bondo & mean & 0.29 & 0.34 & 0.63 & 1.91 & 3.8 \\
\hline Kericho & mean & 0.01 & 0.01 & 0.02 & 1.14 & 6.7 \\
\hline $\mathrm{P}$ value & & $\mathrm{p}<0.001$ & $\mathrm{p}<0.001$ & $\mathrm{p}<0.001$ & $\mathrm{p}<0.05$ & $\mathrm{p}<0.001$ \\
\hline
\end{tabular}


Typical dietary recommendations for Omega 3 Fatty Acids are 0.3 to $0.5 \mathrm{~g}$ of EPA+DHA. which is met by the Bondo population in this study but not so for the Kericho population.

Relationship between 2 hour post-prandial glucose and the consumption of DHA (C22,6): According to Pearson correlation coefficient, there was a significant negative correlation between 2 hour post-prandial glucose levels and consumption of DHA (C22.6), $(r=-0.111, p<0.05)$ in both populations. For males the correlation between DHA consumption and 2 hour post-prandial glucose was $(\mathrm{r}=-0.226, \mathrm{p}<0.05)$ and $(r=-0.049, p=0.533)$ for females. The correlation between DHAconsumption and 2 hour post-prandial glucose was not significant in females.

Relationship between 2 hour post-prandial glucose and the consumption of EPA $(C 20,5)$ : The correlation between EPA consumption and 2 hour post-prandial glucose levels was $(r=-0.123, p<0.05)$. For males, the correlation between consumption of EPA and 2 hour post-prandial levels was very highly significant, at $\mathrm{r}=-0.237 . \mathrm{p}<0.001$ ) and for females, there was also a negative correlation though it was not significant, at $\mathrm{r}=-0.056 . \mathrm{p}=0.476$ ).

Relationshipbetween 2 hour post-prandial glucose and the consumption of other polyunsaturated fatty acids (PUFAs): There was an overall significant negative correlation between levels of 2 hour post- prandial glucose and the consumption of other polyunsaturated fatty acids (PUFAs), among both populations $(\mathrm{r}=-0.128, \mathrm{p}<0.05)$. Among the males, the correlation was $r=-0.184$ at $\mathrm{p}<0.05$ and $(\mathrm{r}=0.010, \mathrm{p}=0.898)$ among the females. These results show that among the females, there was no relationship between the levels of 2 hour post-prandial glucose and the consumption of other polyunsaturated fatty acids (PUFAs).

Relationship between 2 hour post-prandial glucose and the consumption of saturated fats: In both populations, the correlation between 2 hour post-prandial glucose and the consumption of saturated fats was $(\mathrm{r}=-0.002$. $\mathrm{p}=0.973)$. It was $(\mathrm{r}=-0.043, \mathrm{p}=0.630)$ for males and $(\mathrm{r}=$ $0.1009, \mathrm{p}=0.166$ ) for females. These results clearly show there is no link between saturated fat consumption and the level of post-prandial glucose.

\section{DISCUSSION}

This study clearly illustrates different prevalence of IGT (2hour post-prandial glucose of between 7.8 $\mathrm{mmol} / \mathrm{l}-11.1 \mathrm{mmol} / \mathrm{l}$ ) among two rural populations sharing similar environmental factors, except for separation in dietary and other cultural practices. The Luo community in Bondo district exhibited an IGT prevalence of $4.8 \%$, while the Kipsigis community in
Kericho districthad a prevalence of $11.8 \%$. The results also show large cross-ethnic differences in intake of n-3 fatty acids among the Bondo and the Kericho populations. It can be hypothesised that the highly significant differences in prevalence of IGT observed between the Kipsigis community of Kericho and the Luo in Bondo is related to differences in lifestyle, with a special emphasis on diet.

Their respective fish and fish product consumption was differing markedly, with $29.3 \%$ of the surveyed population in Bondo taking fish at least once a day with a mean consumption of $0.63 \mathrm{~g} n-3 F A$, as compared to only $0.7 \%$ of the Kericho population, with a mean consumption of $0.02 \mathrm{~g}$ of n-3FA. The fish products are consumed in large quantities all year around Bondo district whereas in Kericho, they generally consume small quantities of fish. In the United States, the intake of total omega-3 fatty acids is approximately $1.6 \mathrm{~g}$, and of this, alpha-linolenic acid accounts for approximately $1.4 \mathrm{~g}$, and only 0.1 to $0.2 \mathrm{~g}$ comes from EPA and DHA (19).

The Kericho population had a greater consumption of culturally preserved milk known as mursik as well as a high consumption of sugarcane, as the area of study is located within a sugar plantation belt. This compares well with a study that involved comparison of blood lipids and risk for cardiovascular disease (CVD) among thouree populations, one of which had a higher consumption of marine products. Thestudy subjects in Canada included the Quebecers, the Cree of James Bay, and the Inuit of Nunavik. Significant differences in levels of CVD risk factors were found among these thouree populations. The Inuit showed the lowest risk status for CVD compared with the Cree and the Quebecers, despite the high prevalence of cigarette smoking and obesity. Daily fish intakes varied significantly among the thouree groups, averaging 13,60 , and $131 \mathrm{~g}$ for the Quebecers, the Cree and the Inuit. respectively (20).

The significant negative correlation between 2 hour post-prandial glucose levels and consumption of DHA $(\mathrm{C} 22,6),(\mathrm{r}=-0.111, \mathrm{p}<0.05)$ was an indication that higher consumption levels of DHA significantly yielded lower levels of 2 hour post-prandial glucose and lower levels of consumption of DHA yielded significantly higher levels of 2 hour post-prandial glucose. This was also the case between EPA and PUF A consumption and 2 hour post-prandial glucose levels at $(\mathrm{r}=-0.123, \mathrm{p}<0.05)$ and $(\mathrm{r}=0.128, \mathrm{p}<0.05)$ respectively. This implies that $\mathrm{n}-3$ fatty acids (both DHA and EPA), as well as PUF A are beneficial to health and can protect against IGT, since those who consumed higher levels of the nutrients recorded lower levels of the risk of T2DM.

In both populations, the correlation between 2 hour post-prandial glucose and the consumption of saturated fats was $(r=-0.002, p=0.973)$, which clearly indicates no link between saturated fat consumption 
and the level of post-prandial glucose. The saturated fat ingested did not affect the level of post-prandial glucose. Higher proportions of saturated fatty acids intake have been associated with higher fasting insulin concentrations (11) and a lower insulin sensitivity index and consequently, higher risk of type 2 diabetes (12). On the other hand, there are several studies, which show no association between diabetes risk and total saturated fat intake (13-15). It was important for this study to be able to establish the risk of T2DM occasioned by saturated fat vis-a-vis polyunsaturated fats like 03FA.

Women in this study demonstrated higher prevalence of IGT than men $(\mathrm{P}<0.05)$, with the women among the Kipsigis of Kericho demonstrating an even higher prevalence than their Bondo counterparts $(17.9 \%)$. The same is true for the Kericho men against their Bondo counterparts. In Bondo the females also demonstrated higher levels of 2 hour post-prandial glucose than males and it was the same case in Kericho. The overall levels of post-prandial glucose among the women were also higher than those of men (Figure $1)$. In a study of over 60 year old women $(n=2,595)$ in Goteborg Sweden, the prevalence of IGT was 14.4\% and they also recorded higher values of BMI, waist girth and blood pressure. Among these women, 40\% recorded having both IGT and FBG (21).

In Australia where the prevalence of abnormal glucose intolerance is one of the highest yet reported from a developed nation, $17.4 \%$ of the men and $15.4 \%$ of the women from a national sample of 11,247 were found to be suffering from IGT (22). Age and gender were confirmed to be very strongly correlated to impaired glucose tolerance as earlier observed in a study among rural and urban populations in Luzon, Philippines (23).

In conclussion, the levels of IGT were significantly lower $(\mathrm{P}<0.001)$ among the Luo, than among the Kipsigis, and also higher among the women than the men $(\mathrm{P}<0.001)$. There was also evidence of significant inverse relationship between IGT and consumption of $\mathrm{n}-3 \mathrm{~F} \mathrm{~A}$ and polyunsaturated fatty acids (PUFA) but no association between saturated fats intake and IGT. The saturated fat ingested did not affect the level of post-prandial glucose. The Luo who consumed higher n-3FA amounts, recorded lower levels of IGT than the Kipsigis who had significantly lower consumption.

We recommend that effective screening methods should be used at the existing health units to determine risk factors of type 2 diabetes mellitus like IGT among patients. This could help in advising them accordingly on lifestyle changes, especially concerning diet and beneficial fats.

Special attention should be paid to female subjects thourough control of modifiable risk factors such as IGT and this should be given the same emphasis that is given to cancers associated with the female reproductive system like cervical or breast cancer since unchecked IGT could lead to the equally detrimental T2DM.

Like the "Know your status" campaign that has been adopted for the prevention and check of the spread of HIV, there should be a similar '"know your status" campaign for T2DM because most people are unaware of their diabetes status, only coming to know after enrollment to a study. This phenomenon ensures that even those at the borderline stages of IGT and impaired fasting glucose (IFG) who can be salvaged, are not detected and eventually they progress to diabetes, consequently succumbing to microvascular and macrovascular complications.

\section{ACKNOWLEDGEMENTS}

The authors would like to thank the participants, as well as the research assistants of this study, in both Bondo and Kericho districts for their valuable time and collaboration during the research. Several people were also instrumental in mobilisation of participants in the study areas; we would like to thank especially Dr. A. Rotich, District Medical Officer of Health (Kericho) and Dr. B. Kipruto, District Medical Officer of Health (Bondo) for their tireless assistance thouroughout the duration of this project. We would also like to thank the respective Public Health Officers, Mr. J. Chepkwony (Kericho) and Mr. O. Walter (Bondo), who were instrumental in the project implementation. Appreciation is also accorded to Mr. T. Okech, Ms P. Awuor and Ms R. Bitonga for proficiently handling sample collection. The study was funded by Kenyatta University, Kenya.

\section{REFERENCES}

1. WHO Consultation Group. Definition, diagnosis and classification of diabetes mellitus and its complications. Part 1: Diagnosis and classification of diabetesmellitus. Geneva:World HealthOrganisation. 1999.

2. Ceesay, M. M., Morgan, M. W., Kamanda, M. O. et al. Prevalence of diabetes in rural and urban populations in southern SierraLeone: a preliminary survey. Trop. Med. Intern. Health. 1997; 2: 272.

3. Amos, A.F., McCarty, D.J. and Zimmet, P. The rising global burden of diabetes and its complications: estimates and projections to the year 2010. Diabet $M$ independent of sex in black NIDDM subjects. Am. J. Physiol. 1997; 273: E425-E432.

4. Harris, M.I. and Eastman, R.C. Early detection of undiagnosed diabetes mellitus: A U.S. perspective. Diab. Metabolism Res. Rev. 2001; 26: 230-236.

5. Motala, A. A., Omar, M. A., and Pirie, F.J. Diabetes in Africa. Epidemiology of type 1 and type 2 diabetes in Africa. J. Cardiovasc. Risk. 2003; 10: 77-83. 
6. World Health Organization: Screening for Type 2 Diabetes. Report of a World Health Organization and International Diabetes Foundation meeting, WHO/NMH/MNC/03.1. Geneva. Switzerland. 2003; pp. 1-48.

7. Rao, S.S., Disraeli, P., and Mcgregor, C. Impaired glucose tolerance and impaired fasting glucose. Amer. Fam. Phys. 2004; 69: 8.

8. Hussain, A., Rahim, M. A., Azad Khan, A. K. et al. Type 2 diabetes in rural and urban population: diverse prevalence and associated risk factors in Bangladesh. Diab. Med. J. 2005; 22: 931.

9. Gamm, L., Hutchinson, L., Bellamy, G., et al. Rural healthy people 2010:Identifying rural health priorities and models for practice. J. Rural Health. 2002; 18: 914.

10. Kris-Etherton, P. M., Harris, W.S., and Appel, L. J. For the nutrition committee fish consumption, fish oil, omega-3 fatty acids and cardiovascular disease. J. Amer. Heart Assoc. (Circulation. 2002;106: 2747-2757.) Circulation is available at $h t t p: / / w w w$. circulationaha.org.

11. Marshall,J.A., Bessesen, D.H. and Hamman, R. F.High saturated fat and low starch and fibre are associated with hyperinsulinemia in a non-diabetic population: the San Luis Valley. Diabetes Study Diabetologia. 1997; 40: 430 - 438.

12. Lovejoy, J. and DiGirolamo, M. Habitual dietary intake and insulin sensitivity in lean and obese adults. Amer. J. Clin. Nutr. 1992; 55: 1174 - 1179.

13. Feskens, E. J., Bowles, C.H. and Kromhout, D. Inverse association between fish intake and risk of glucose intolerance in normoglycemic elderly men and women. Diabetes Care. 1991; 14: 935 - 941.

14. Salmeron, J., Hu, B., Manson, J., et al. Dietary fat intake and risk of type 2 diabetes mellitus in women. Amer. J. Clin. Nutr. 2001; 73: 61019-61026.
15. Colditz, G.A., Manson, J.E., Stampfer, M. J., et al. Diet and risk of clinical diabetes in women. Amer. J. Clin. Nutr. 1992; 55: 1018 - 1023.

16. Government of Kenya. The 1999 Population Census.

17. Faul, F., Erdfelder, E., Lang, A. and Buchner, A. G. Power 3: Aflexible statistical power analysis for social behavioural and biomedical sciences. Behaviour Res. Methods. 2007; 39: 175-191.

18. Sehmi, J.K. National Food Composition Tables and the Planning of Satisfactory Diets. Nairobi. Government of Kenya Press. 1993

19. Kris-Etherton, P.M., Harris, W.S. and Appel, L. J., For the nutrition committee fish consumption, fish oil, omega-3 fatty acids and cardiovascular disease. J. Amer. Heart Association. Circulation. 2002; 106: 2747-2757. Circulation is available at http://www. circulationaha.org

20. Dewailly, E., Blancheta, C., Gingrasa, S., Lemieuxc, S., and Holub, B.J. Fish consumption and blood lipids in thouree ethnic groups of Quebec (Canada). Lipids. 2003; 38: 359-365.

21. Brohall, G., Behre, C. J. and Hulhe, J. Prevalence of diabetes and impaired glucose tolerance in 64 year old Swedish woman. Diabetes Care. 2006; 29: 2.

22. Dunstan, D.W., Zimmet, P.Z. and Welborm, T.A. The rising prevalence of diabetes and IGT. Diabetes Care. 2002; 25: 5.

22. Baltazar, J. C., Ancheta, C. A., Aban, I. B., Fernando, R. E. and Baquilod, M. M. Prevalence and correlates of diabetes mellitus and impaired glucose tolerance among adults in Luzon, Philippines. Diabetes. Res. Clin. Pract. 2004; 64: 107-115. 